\title{
Production of bacterial cellulose and enzyme from waste fiber sludge
}

\author{
Adnan Cavka ${ }^{1,2+}$, Xiang Guo ${ }^{1,3 \dagger}$, Shui-Jia Tang ${ }^{3}$, Sandra Winestrand ${ }^{2}$, Leif J Jönsson ${ }^{1,2^{*}}$ and Feng Hong ${ }^{1,3^{*}}$
}

\begin{abstract}
Background: Bacterial cellulose (BC) is a highly crystalline and mechanically stable nanopolymer, which has excellent potential as a material in many novel applications, especially if it can be produced in large amounts from an inexpensive feedstock. Waste fiber sludge, a residue with little or no value, originates from pulp mills and lignocellulosic biorefineries. A high cellulose and low lignin content contributes to making the fiber sludge suitable for bioconversion, even without a thermochemical pretreatment step. In this study, the possibility to combine production of BC and hydrolytic enzymes from fiber sludge was investigated. The BC was characterized using field-emission scanning electron microscopy and $X$-ray diffraction analysis, and its mechanical properties were investigated.

Results: Bacterial cellulose and enzymes were produced through sequential fermentations with the bacterium Gluconacetobacter xylinus and the filamentous fungus Trichoderma reesei. Fiber sludges from sulfate (SAFS) and sulfite (SIFS) processes were hydrolyzed enzymatically without prior thermochemical pretreatment and the resulting hydrolysates were used for BC production. The highest volumetric yields of BC from SAFS and SIFS were 11 and $10 \mathrm{~g} / \mathrm{L}$ (DW), respectively. The BC yield on initial sugar in hydrolysate-based medium reached $0.3 \mathrm{~g} / \mathrm{g}$ after seven days of cultivation. The tensile strength of wet $\mathrm{BC}$ from hydrolysate medium was about $0.04 \mathrm{MPa}$ compared to about $0.03 \mathrm{MPa}$ for BC from a glucose-based reference medium, while the crystallinity was slightly lower for BC from hydrolysate cultures. The spent hydrolysates were used for production of cellulase with T. reesei. The cellulase activity (CMCase activity) in spent SAFS and SIFS hydrolysates reached $5.2 \mathrm{U} / \mathrm{mL}(87 \mathrm{nkat} / \mathrm{mL})$, which was similar to the activity level obtained in a reference medium containing equal amounts of reducing sugar.

Conclusions: It was shown that waste fiber sludge is a suitable raw material for production of bacterial cellulose and enzymes through sequential fermentation. The concept studied offers efficient utilization of the various components in fiber sludge hydrolysates and affords a possibility to combine production of two high value-added products using residual streams from pulp mills and biorefineries. Cellulase produced in this manner could tentatively be used to hydrolyze fresh fiber sludge to obtain medium suitable for production of BC in the same biorefinery.
\end{abstract}

Keywords: Bacterial cellulose, Gluconacetobacter xylinus, Enzyme production, Cellulase, Trichoderma reesei, Fiber sludge

\section{Background}

Production of high value-added materials from residual streams originating from renewable feedstock is an interesting possibility, which has the prospective of becoming an integral part of existing pulp mills and lignocellulosic biorefineries. One such material is

\footnotetext{
*Correspondence: leif.jonsson@chem.umu.se; fhong@dhu.edu.cn

${ }^{\dagger}$ Equal contributors

'China-Sweden Associated Research Laboratory in Industrial Biotechnology, College of Chemistry, Chemical Engineering and Biotechnology, Donghua University, Shanghai 201620, China

${ }^{2}$ Department of Chemistry, Umeå University, SE-901 87, Umeå, Sweden Full list of author information is available at the end of the article
}

bacterial cellulose $(\mathrm{BC})$, which is a nano-structured material produced by various species of acetic acid bacteria [1]. BC is mainly built up by microfibrils, which are around $2-4 \mathrm{~nm}$ in diameter and which in turn build up fibers with an approximate size of less than $100 \mathrm{~nm}$ [2]. The fine and well-ordered structure of $\mathrm{BC}$ offers several advantages when it is used in matrices with other materials, such as low thermal expansion and superior reinforcement [3]. Already today, $\mathrm{BC}$ has reached a wide array of applications, such as health food, cosmetics, pharmaceutical and biomedical products, reinforcement of high-quality papers, diaphragms for electro-acoustic

\section{Biomed Central}


transducers, paint additives, coatings, reinforcement for optically transparent films, and proton-conducting membranes of fuel cells [1,3-7]. The future potential for $\mathrm{BC}$ is even wider than the already existing applications, especially if it can be produced in large amounts from an inexpensive feedstock, and may include areas such as specialty textiles [8], advanced functional materials, and packaging.

Production of bacterial cellulose from agricultural products and residues, which include konjak glucomannan [9], wheat straw $[10,11]$, and cotton-based waste textiles [12], has previously been demonstrated. An advantage of using agricultural or industrial residual streams as feedstock for production of bacterial cellulose is the low cost of the raw material. When lignocellulosic feedstocks are pretreated at high temperature and high pressure they give rise to inhibitory compounds due to breakdown of polysaccharides and lignin. In the studies of Hong and Qiu [9] and Hong et al. [10], the hydrolysates obtained through acid hydrolysis of konjak glucomannan and wheat straw had to be detoxified using overliming in order to enable bacterial growth and production of $\mathrm{BC}$.

Waste fiber sludge is a residual material originating from pulp mills and lignocellulosic biorefineries. Fiber sludge consists mainly of cellulose and hemicellulose, and usually has a low content of lignin $(\leq 5 \%)$. Due to their composition and structure, fiber sludges are usually easy to be hydrolyzed enzymatically without prior thermochemical pretreatment, and could potentially yield hydrolysates with high glucose concentrations and low content of inhibitory compounds. A low content of inhibitory compounds should be advantageous for the bacterial strains used for production of BC. There are, however, drawbacks associated with enzymatic hydrolysis, especially the high cost for the hydrolytic enzymes used in the process.

The objectives of this study were to investigate the appropriateness of waste fiber sludge for production of $\mathrm{BC}$, and the possibility to combine the production of $\mathrm{BC}$ with production of hydrolytic enzymes useful for degradation of lignocellulose. The fiber sludges used in this study were originated from a pulp mill using a sulfate-based process (kraft pulping) and from a lignocellulosic biorefinery using a sulfite-based process. In addition, we investigated the metabolic preferences of the bacterium, Gluconacetobacter xylinus, used for the production of bacterial cellulose and the filamentous fungus, Trichoderma reesei (Hypocrea jecorina), used for enzyme production by analyzing the consumption of different components in the culture medium. Sequential production of BC and enzyme would potentially give two high value-added products from a residual stream of very low or no value. Production of $\mathrm{BC}$ and enzyme could tentatively also be integrated with biofuel manufacture, which would benefit from production of high value-added co-products and from on-site production of hydrolytic enzymes.

\section{Results and discussion}

Fiber sludges collected from mills operating sulfate- and sulfite-based processes were characterized chemically and subjected to enzymatic hydrolysis without any thermochemical pretreatment. The dry-matter content of the SAFS was $51.7 \%$, while it was $43.7 \%$ for the SIFS. Compositional analysis (Table 1) indicates that SAFS consisted mainly of glucan (69.1\%) and xylan (15.4\%). SIFS consisted mainly of glucan (89.7\%) and contained very low levels of other carbohydrates, such as mannan (2.7\%) and xylan (1.7\%). The content of lignin was low in both SAFS and SIFS (Table 1).

The first experimental series in which G. xylinus was grown on fiber sludge hydrolysates showed that it was advantageous to dilute the hydrolysates in order to facilitate $\mathrm{BC}$ production (Figure 1). The bacterium grew well in all diluted media. The results indicate that G. xylinus consumed similar amounts of reducing sugars in all of the experiments, namely around $20 \mathrm{~g} / \mathrm{L}$ of reducing sugar during seven days of cultivation. The $\mathrm{pH}$ value of the media decreased during the cultivations, from around $\mathrm{pH} 5$ to around $\mathrm{pH} 3$.

The volumetric yield of BC (DW) in undiluted hydrolysate was about $2 \mathrm{~g} / \mathrm{L}$ for both SAFS and SIFS. A twofold dilution of the hydrolysate increased the volumetric $\mathrm{BC}$ yield to $11 \mathrm{~g} / \mathrm{L}$ for SAFS and $10 \mathrm{~g} / \mathrm{L}$ for SIFS, which represents a five-fold increase compared to undiluted hydrolysates (Figure 1A). When the hydrolysate was diluted three-fold, the volumetric yield of BC decreased slightly to around $9 \mathrm{~g} / \mathrm{L}$ for both SAFS and SIFS. A fourfold dilution resulted in a $\mathrm{BC}$ yield of around $8 \mathrm{~g} / \mathrm{L}$ (Figure 1A). The volumetric yield of $\mathrm{BC}(\mathrm{g} / \mathrm{L})$ was not that different in the experiments with diluted hydrolysates. However, the $\mathrm{BC}$ yield on the initial amount of reducing sugar $(\mathrm{g} / \mathrm{g})$ increased with increasing dilution (Figure 1B). The two-fold dilution resulted in a BC yield of around $0.20 \mathrm{~g} / \mathrm{g}$, while the three-fold dilution resulted in an improvement to around $0.22 \mathrm{~g} / \mathrm{g}$. The four-fold dilution resulted in the highest yields, around $0.30 \mathrm{~g}$ of $\mathrm{BC}$ per $\mathrm{g}$ initial reducing sugar. The yield of $B C$ on consumed reducing sugar was $0.5-0.6 \mathrm{~g} / \mathrm{g}$ for the different dilutions of the SAFS hydrolysate. For

Table 1 Composition (\% w/w) of sulfate (SAFS) and sulfite (SIFS) fiber sludges

\begin{tabular}{lccccccc}
\hline $\begin{array}{l}\text { Fiber } \\
\text { sludge }\end{array}$ & Arabinan & Galactan & Glucan & Mannan & Xylan & Lignin & Ash \\
\hline SAFS & 0.3 & 0.2 & 69.1 & 3.3 & 15.4 & 3.5 & 3.6 \\
SIFS & $<0.02$ & 0.1 & 89.7 & 2.7 & 1.6 & 0.8 & 1.7 \\
\hline
\end{tabular}




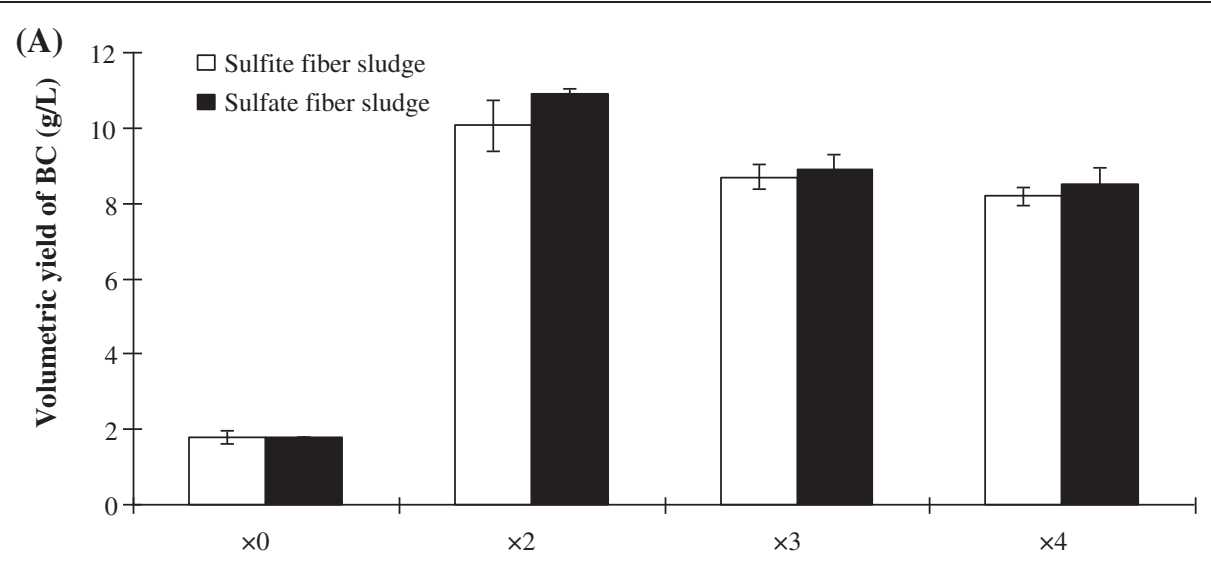

(B)

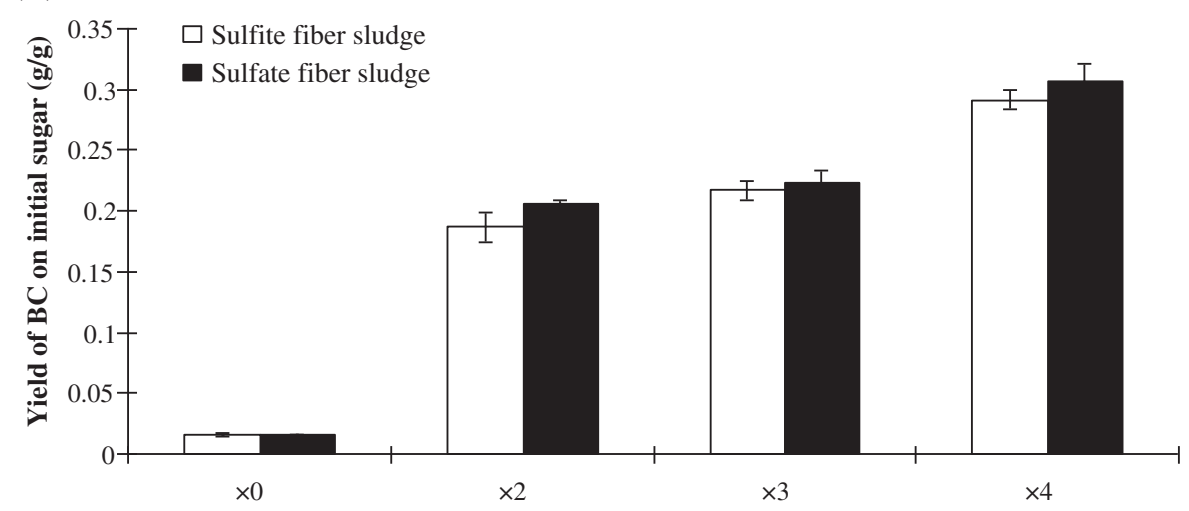

Figure 1 Yields of bacterial cellulose (BC) after seven days of cultivation of $\mathbf{G}$. xylinus. The top graph (A) shows the volumetric yield $[\mathrm{g} B C(\mathrm{DW})$ per $\mathrm{L}]$ and the bottom graph (B) shows the yield on the initial amounts of reducing sugar [g BC (DW) per $g$ initial sugar].

the different dilutions of the SIFS hydrolysate, the yield of $\mathrm{BC}$ on consumed reducing sugar was about $0.4 \mathrm{~g} / \mathrm{g}$.

After evaluating the initial results, the four-fold dilution was selected for further experiments. The second attempt of production of $\mathrm{BC}$ was performed in larger scale and $100 \mathrm{~mL}$ of hydrolysate was used instead of $30 \mathrm{~mL}$. Furthermore, a glucose reference with similar sugar content was included for comparison and the incubation time was increased to 14 days, after which the $\mathrm{BC}$ was collected through filtration and its properties were investigated in order to assess the outcome of the experiments. The results are summarized in Table 2 . Surprisingly, the volumetric BC yield (DW) from the SAFS hydrolysate, $6.23 \mathrm{~g} / \mathrm{L}$, was higher than for the reference cultivation, which reached $4.90 \mathrm{~g} / \mathrm{L}$. The cultivation in SIFS hydrolysate gave $4.65 \mathrm{~g} / \mathrm{L}$, a slightly lower volumetric yield than for the reference. The waterholding capacity of the $\mathrm{BC}$ membranes was almost identical (Table 2). When the thickness of the strips was measured, the results were found to be different. The thickest BC strips, $3.11 \mathrm{~mm}$, were found in the reference medium, which can be compared to $2.83 \mathrm{~mm}$ for the SAFS hydrolysate and $2.59 \mathrm{~mm}$ for the SIFS hydrolysate.
The thickness of $\mathrm{BC}$ membranes is, however, less important than the tensile strength, since the thickness can be influenced by several factors, such as surface area and the amount of water held by the membrane. The BC membranes from SAFS and SIFS hydrolysates had a tensile strength of around $0.04 \mathrm{MPa}$ (Table 2). This was considerably higher than for membranes produced in

Table 2 Properties of BC produced in different media with a four-fold dilution of hydrolysate and after 14 days of fermentation

\begin{tabular}{lccc}
\hline Property/Culture medium & $\begin{array}{c}\text { SAFS } \\
\text { hydrolysate }\end{array}$ & $\begin{array}{c}\text { SIFS } \\
\text { hydrolysate }\end{array}$ & $\begin{array}{c}\text { Reference } \\
\text { medium }\end{array}$ \\
\hline Volumetric yield of BC (g/L) & $6.23 \pm 0.14$ & $4.65 \pm 0.15$ & $4.90 \pm 0.58$ \\
$\begin{array}{l}\text { Water-holding capacity of BC } \\
\text { (\%) }\end{array}$ & $99.5 \pm 1.0$ & $99.4 \pm 2.0$ & $99.5 \pm 0.1$ \\
Thickness of BC strips (mm) & $2.83 \pm 0.20$ & $2.59 \pm 0.20$ & $3.11 \pm 0.22$ \\
Tensile force (N) (wet sheet) & $0.48 \pm 0.09$ & $0.41 \pm 0.08$ & $0.39 \pm 0.05$ \\
Tensile strength (MPa) & $0.042 \pm 0.012$ & $0.040 \pm 0.020$ & $0.031 \pm 0.011$ \\
(wet sheet) & & & \\
Degree of crystallinity (\%) ${ }^{[a]}$ & 60.6 & 66.3 & 78.0 \\
\hline
\end{tabular}

${ }^{\text {a] }}$ Calculations were based on the empirical method found in [26]. 
the reference medium, which exhibited resistance up to around $0.03 \mathrm{MPa}$. Similar results were found previously in a study of $\mathrm{BC}$ production from cotton-based waste textiles [12]. The fact that the tensile strength of $\mathrm{BC}$ produced in glucose-based medium was lower than that of $\mathrm{BC}$ produced in hydrolysates is perhaps due to the lower thickness of the $\mathrm{BC}$ pellicles from the hydrolysate media. The $\mathrm{BC}$ in the hydrolysate media would be able to form a more compact network than in the reference medium.

The degree of crystallinity of the $\mathrm{BC}$ membranes differed depending on the cultivation medium. A higher degree of crystallinity gives rise to a more stable cellulose polymer when it comes to resistance to digestion and breakdown of the polymer. Hence, more crystalline cellulose polymers are also more difficult to solubilize and add functional groups to, which would be required if the cellulose is to be used for many of the potential applications for BC. The analysis of the different membranes showed that the most crystalline cellulose was found in $\mathrm{BC}$ from cultures with reference medium, where the degree of crystallinity was around $78 \%$. The cellulose from SAFS hydrolysate had a crystallinity of around $61 \%$, while the cellulose from SIFS hydrolysate had a crystallinity of around $66 \%$. These results are further supported by scanning electron microscope (SEM) images, which display the structure of the cellulose membranes at a magnification of 20,000 times. Fieldemission scanning electron micrographs (FESEM) of freeze-dried $\mathrm{BC}$ pellicles prepared from reference medium and from SIFS and SAFS hydrolysates are shown in Figure 2A-C. The fracture surface morphology of the $\mathrm{BC}$ pellicles from different media is essentially the same and the histograms (Figure 2a-c) based on the FESEM images illustrate a small average diameter and a relatively narrow diameter distribution for the nanofibers of the $\mathrm{BC}$ pellicles. The fiber distribution data indicate that most of the fibers were in the range 15 to $70 \mathrm{~nm}$, with an average width of 35 to $40 \mathrm{~nm}$.

In the experiment in which the cultures were harvested after 14 days, the yield of $\mathrm{BC}$ on consumed reducing sugar was $0.50 \mathrm{~g} / \mathrm{g}$ for the SAFS hydrolysate and $0.31 \mathrm{~g} / \mathrm{g}$ for the SIFS hydrolysate. The BC yield from the cultures with reference medium was only $0.28 \mathrm{~g} / \mathrm{g}$. The yield of $\mathrm{BC}$ on the initial concentration of reducing sugar was $0.22 \mathrm{~g} / \mathrm{g}$ for the SAFS hydrolysate,

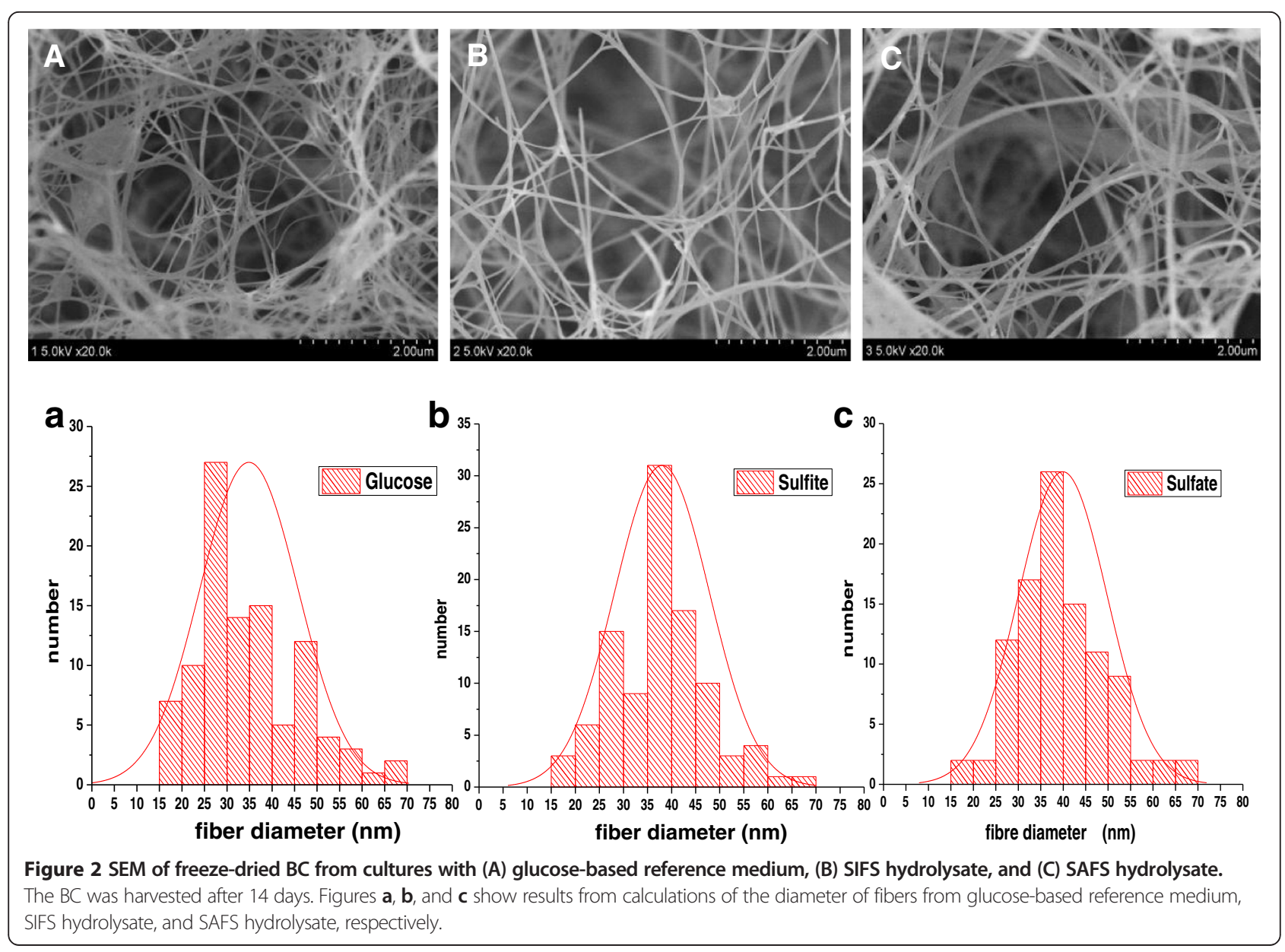


$0.17 \mathrm{~g} / \mathrm{g}$ for the SIFS hydrolysate, and $0.18 \mathrm{~g} / \mathrm{g}$ for the reference medium.

The results obtained in our study compare well to results achieved in other studies where various substrates have been used for production of BC. Keshk and Sameshima [13] studied the ability of G. xylinus ATCC10245 to produce BC using sixteen different carbon sources including monosaccharides, polysaccharides, and alcohols. Only four of these carbon sources turned out to be useful for production of $\mathrm{BC}$. The highest $\mathrm{BC}$ yield on the consumed amount of carbon source, $0.287 \mathrm{~g} / \mathrm{g}$, was achieved with glycerol [13]. Fructose, glucose, and inositol gave $\mathrm{BC}$ yields amounting to $0.153 \mathrm{~g} / \mathrm{g}, 0.087 \mathrm{~g} / \mathrm{g}$, and $0.078 \mathrm{~g} / \mathrm{g}$, respectively. The high yield achieved with glycerol could be attributed to the low consumption rate for this carbon source. Thompson and Hamilton [14] compared two different G. xylinus strains, ATCC10821 and ATCC23770, and their ability to grow on various carbon sources, such as potato effluents, cheese whey permeate, and sugar beet raffinate. Their results indicated that the highest yield for ATCC10821 was achieved after seven days of incubation, while ATCC23770 gave better yield after 14 days. The best results were achieved with potato effluents (starch) and ATCC23770, which gave a BC yield on consumed glucose of $0.27 \mathrm{~g} / \mathrm{g}$ after 14 days, nearly the same yield as that obtained from a cultivation on optimized glucose medium [14]. This can be compared to our study, where the yields on consumed reducing sugars for the cultivations on SAFS $(0.50 \mathrm{~g} / \mathrm{g})$ and SIFS $(0.31 \mathrm{~g} / \mathrm{g})$ hydrolysates were higher than that of the cultivation on glucose-based reference medium $(0.28 \mathrm{~g} / \mathrm{g})$. This suggests that $\mathrm{BC}$ production from residual low-value streams from forest biorefineries performs well compared to $\mathrm{BC}$ production from residues originating from the agricultural sector.

The analysis of monosaccharides is summarized in Table 3. The results indicate that glucose was the main nutrient source and that it was consumed efficiently in all cultivations. The analysis also suggests that some of the xylose was consumed. The utilization of xylose by G. xylinus is not well understood but it is suggested in the literature that most G. xylinus strains have poor ability to utilize xylose $[15,16]$. The metabolic pathway presented by Ross et al. [17] suggests that G. xylinus has the ability to utilize xylose. It has been proposed that xylose is mainly used as a source of energy for the bacterium, as it is consumed by G. xylinus through conversion into glyceraldehyde-3-phosphate, which in turn ends up in the tricarboxylic acid cycle (TCA) as acetyl Co-A after several other reactions [17]. Our study of complex fermentation media composed of fiber sludge hydrolysates further supports the suggestion that G. xylinus does convert xylose. The analysis of the media before and after fermentation with G. xylinus indicates that the consumption of xylose was around $2 \mathrm{~g} / \mathrm{L}$ during 14 days of fermentation (Table 3).

The concept of sequential fermentation has previously been successful for production of ethanol and enzymes from lignocellulosic feedstock [18] and waste fiber sludge [19]. This concept offers several potential advantages. These include efficient utilization of the various components in the cultivation medium by two different microorganisms. In the present study, the possibility to produce two value-added products, BC and enzymes, was also investigated, and $T$. reesei was used in the second step rather than Aspergillus niger (A. niger), which was used in previous studies $[18,19]$. With the production of enzymes in the second fermentation step, the need of external supply of enzymes for hydrolysis of fiber sludge would decrease, as enzymes could tentatively be supplied through on-site enzyme production. The results achieved in this study indicate that the spent SAFS hydrolysate served as a good medium for enzyme production with $T$. reesei. The cellulase activity after 6 days of fermentation reached $5.2 \mathrm{U} / \mathrm{mL}$ ( $87 \mathrm{nkat} / \mathrm{mL}$ ) (Figure 3). T. reesei seemed to grow well in the medium despite its low content of easily accessible monosaccharides that the fungus could use as carbon source (cf. Table 3). However, in addition to monosaccharides and acetic acid (Table 3), the medium may also contain disaccharides, oligosaccharides, and other substances that the fungus

Table 3 Analysis of media used for cultivation of G. xylinus

\begin{tabular}{|c|c|c|c|c|c|c|}
\hline \multicolumn{7}{|c|}{ A. Prior to fermentation with G. xylinus and with a four-fold dilution of the hydrolysates. } \\
\hline Media/Composition & Glucose (g/L) & Xylose $(\mathrm{g} / \mathrm{L})$ & Arabinose (g/L) & Galactose (g/L) & Mannose (g/L) & Acetic acid (g/L) \\
\hline SAFS hydrolysate & $14.1 \pm 0.3$ & $3.3 \pm 0.1$ & $<0.1$ & $<0.1$ & $<0.1$ & $<0.1$ \\
\hline SIFS hydrolysate & $17.6 \pm 0.2$ & $0.2 \pm 0.1$ & $<0.1$ & $<0.1$ & $<0.1$ & $<0.1$ \\
\hline Reference medium & $18.3 \pm 0.3$ & - & - & - & - & - \\
\hline \multicolumn{7}{|c|}{ B. After 14 days fermentation with G. xylinus (with a four-fold dilution of the hydrolysates). } \\
\hline Media/Composition & Glucose $(g / L)$ & Xylose $(\mathrm{g} / \mathrm{L})$ & Arabinose (g/L) & Galactose $(g / L)$ & Mannose (g/L) & Acetic acid $(g / L)$ \\
\hline SAFS hydrolysate & $<0.1$ & $1.8 \pm 0.1$ & $<0.1$ & $<0.1$ & $<0.1$ & $<0.1$ \\
\hline SIFS hydrolysate & $<0.1$ & $0.2 \pm 0.1$ & $<0.1$ & $<0.1$ & $<0.1$ & $<0.1$ \\
\hline Reference medium & $0.6 \pm 0.1$ & - & - & - & - & - \\
\hline
\end{tabular}



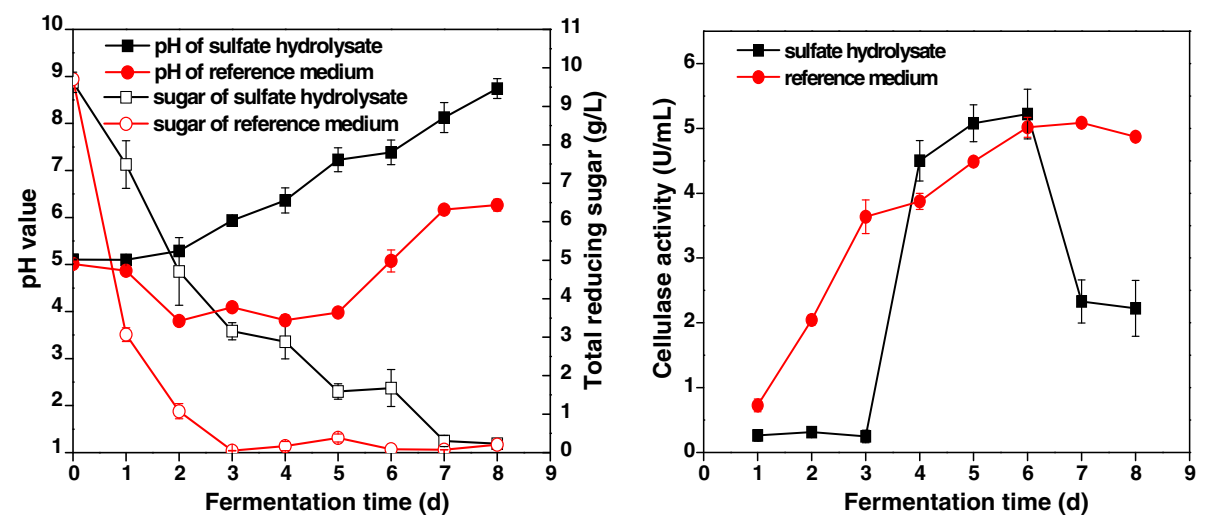

Figure 3 Cultivations of $T$. reesei in SAFS spent hydrolysate and reference medium supplemented with $2 \%$ waste fiber sludge (SAFS).

The figure shows the concentration of reducing sugar and the $\mathrm{pH}$ value (left) and the cellulase (CMCase) activity (right).

could utilize as carbon source. The glucose-based reference medium and the spent SAFS hydrolysate supplemented with fresh sulfate fiber sludge produced almost equal levels of cellulase activity (Figure 3). Cultivations in glucose-based reference medium supplemented with sulfite fiber sludge did exhibit higher activity (Figure 4) than the cultivations in reference medium with sulfate fiber sludge or spent SAFS hydrolysate medium (Figure 3), but the cultivations in spent SIFS did not result in any substantial enzyme activity (Figure 4). These results were somewhat surprising, since it is not clear that the media contained compounds that inhibit $T$. reesei. Analysis of the raw material showed that none of the fiber sludges contained any detectable concentrations of sulfite $[<5 \mathrm{mg} / \mathrm{kg}$ (DW)]. Both fiber sludges contained some sulfate, namely $100 \mathrm{mg} / \mathrm{kg}$ (DW) for the SAFS and $200 \mathrm{mg} / \mathrm{kg}$ for the SIFS. As only very small amounts $(2 \% \mathrm{w} / \mathrm{v})$ of the sludges were added as supplement to the cultivation media used for enzyme production, the sulfate content is unlikely to have had any negative effect on the microorganism. Since reducing sugar was consumed and the $\mathrm{pH}$ changed (Figure 4), the problem may instead be related to cellulase production.

An attempt was made to improve enzyme production by $T$. reesei by dilution of the spent SIFS medium. With a two-fold dilution with water, addition of $2 \%(w / v)$ SIFS, and adjustment of the level of reducing sugars to $10 \mathrm{~g} / \mathrm{L}$ using glucose, $T$. reesei produced a cellulase activity level of $5.2 \mathrm{U} / \mathrm{mL}$ (Figure 5) after 4 days of cultivation, the same level of activity that was obtained using spent SAFS medium. More research is needed to elucidate why undiluted spent SIFS medium inhibited or failed to induce enzyme production.

Several other studies have been performed with $T$. reesei Rut C-30 and complex carbon sources derived from lignocellulose. Shin et al. [20] investigated several different cellulose-based media. In one of these experiments, a mixture of milled newspaper (2\%) and lactose (1\%) was used as substrate for enzyme production and the highest activity reached was $30 \mathrm{nkat} / \mathrm{mL}(1.8 \mathrm{FPU} / \mathrm{mL})$. The same
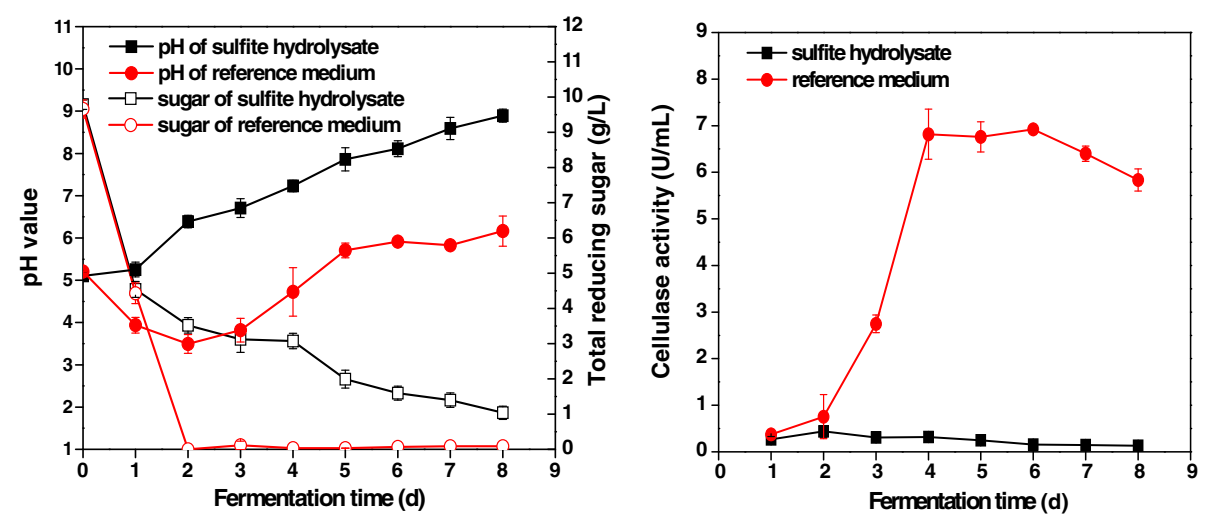

Figure 4 Cultivations of $T$. reesei in SIFS spent hydrolysate and reference medium supplemented with $2 \%$ waste fiber sludge (SIFS). The figure shows the concentration of reducing sugar and the $\mathrm{pH}$ value (left) and the cellulase (CMCase) activity (right). 


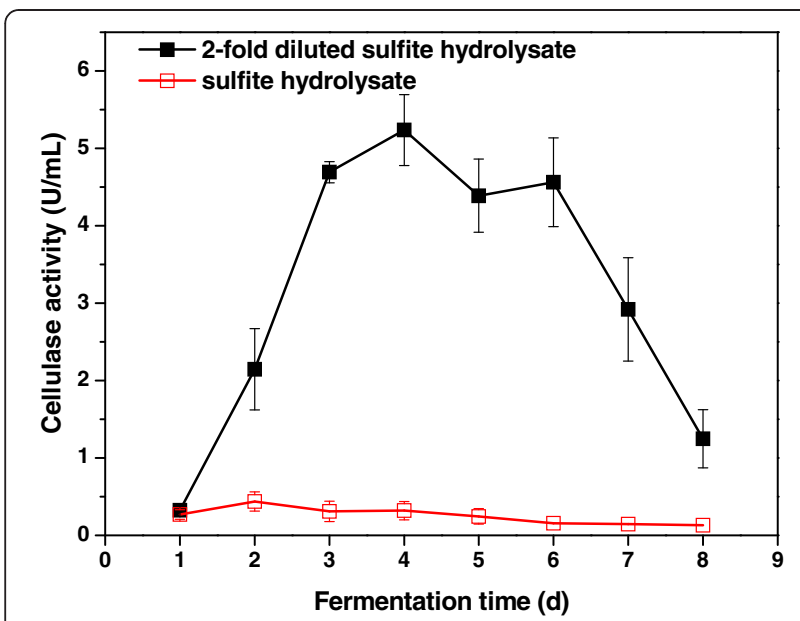

Figure 5 Cellulase (CMCase) activity in cultivations of $T$. reesei in SIFS spent hydrolysate with and without dilution of the medium.

study reported about experiments performed with fiber residues from hydrolyzed office paper $(2 \%)$, in which the highest enzymatic activity was $45 \mathrm{nkat} / \mathrm{mL}(2.7 \mathrm{FPU} / \mathrm{mL})$. Furthermore, pretreated newspaper (1\%) and pretreated oak wood (2\%) were also used for enzyme production in the same study. In experiments with newspaper and oak media, the cellulase activity reached levels of $25 \mathrm{nkat} / \mathrm{mL}$ (1.5 FPU $/ \mathrm{mL})$ and $\sim 72 \mathrm{nkat} / \mathrm{mL}(4.3 \mathrm{FPU} / \mathrm{mL})$, respectively. Pretreated wood has been used for enzyme production with $T$. reesei Rut C-30 in other studies as well. Szengyel et al. [21] used steam-pretreated willow as substrate and achieved $30 \mathrm{nkat} / \mathrm{mL}(1.8 \mathrm{FPU} / \mathrm{mL})$ as the highest activity. This was obtained in experiments where $50 \%$ fibrous pretreated willow was mixed with $50 \%$ of concentrated filtrate (liquid). The medium contained around $20 \mathrm{~g} / \mathrm{L}$ of carbohydrate [21]. Softwood has also been used for enzyme production in a similar manner. Szengyel et al. [22] used steam-pretreated spruce as the carbon source. Several different experiments were performed and $2 \%$ washed steam-pretreated spruce gave the highest activity, namely $\sim 13 \mathrm{nkat} / \mathrm{mL}(0.8 \mathrm{FPU} / \mathrm{mL})$. Although it is evident that a variety of cellulosic media can be used for enzyme production with $T$. reesei, our study differs from the others by the utilization of a waste stream (spent hydrolysate) and by that the enzyme production step was preceded by a BC production step, which makes the enzymes a secondary product.

\section{Conclusions}

In conclusion the results of this study show that there is a great potential in utilizing waste fiber sludge for coproduction of bacterial cellulose and enzymes. Fiber sludge serves as a low cost and abundant raw material which is easily hydrolyzed to sugars without pretreatment. The results also indicate that production of $\mathrm{BC}$ from fiber sludge hydrolysates gives a cellulose polymer displaying superior properties compared to the one produced from a glucose-based reference medium. Conditioning of hydrolysates and optimization of the cultivation conditions are likely to result in higher volumetric yields than what reported here and deserve attention in future studies.

\section{Methods}

\section{Fiber sludges}

The waste fiber sludges that were used in this study were kindly provided by two different European mills, one pulp and paper mill using a sulfate-based process (SAFS) and a lignocellulosic biorefinery using a sulfite-based process (SIFS). The characterization and analysis of the feedstocks and the content of monosaccharides, lignin and ash was performed by MoRe Research (Örnsköldsvik, Sweden).

\section{Enzymatic hydrolysis}

The hydrolysis of the fiber sludges was performed enzymatically without any prior thermochemical pretreatment. Initially, $290 \mathrm{~g}$ of moist SAFS with a dryweight content of $51.7 \%$ were mixed with $693.8 \mathrm{~g}$ of citrate buffer $(0.05 \mathrm{M}, \mathrm{pH} 5.0)$, while $343 \mathrm{~g}$ of moist SIFS with a dry-weight content of $43.7 \%$ were mixed with $640.8 \mathrm{~g}$ of the citrate buffer. The fiber sludges were mixed in 2-L shake flasks, the final dry-matter content was $15 \%(\mathrm{w} / \mathrm{w})$, and the total content per shake flask was $1 \mathrm{~kg}$. The enzyme preparation used for hydrolysis was Cellic CTec2 (Novozymes, Bagsvaerd, Denmark). The enzyme preparation was added to a final concentration of $1.6 \%(\mathrm{w} / \mathrm{w})$ of the reaction mixture, which corresponded to $10 \mathrm{FPU} / \mathrm{g}$ biomass (dry weight of waste fiber sludge). The flasks were incubated with orbital shaking (Ecotron, Infors AG, Bottmingen, Switzerland) at $50^{\circ} \mathrm{C}$ and 150 revolutions per minute (rpm) for $48 \mathrm{~h}$. The glucose level during hydrolysis was monitored using a glucometer (Glucometer Elite XL, Bayer Healthcare, Leverkusen, Germany). After hydrolysis, the slurries were centrifuged (Allegra $\mathrm{X}-22 \mathrm{R}$, Beckman Coulter, Brea, CA, USA) at $4^{\circ} \mathrm{C}$ and $4,200 \mathrm{~g}$ for $10 \mathrm{~min}$ to recover the liquid fractions. The $\mathrm{pH}$ of the liquid fractions was adjusted to 2.0 with sulfuric acid, and they were then stored in a freezer before further processing.

\section{Production of bacterial cellulose}

Production of BC was performed using Gluconacetobacter xylinus (Acetobacter xylinus) ATCC 23770 (American Type Culture Collection, Manassas, VA, USA). A series of $100-\mathrm{mL}$ flasks were filled with $30 \mathrm{~mL}$ fiber sludge 
hydrolysate and supplemented with $5 \mathrm{~g} / \mathrm{L}$ yeast extract and $3 \mathrm{~g} / \mathrm{L}$ tryptone. Fiber sludge hydrolysates were either undiluted or diluted two-fold, three-fold and fourfold. The flasks were autoclaved at $105^{\circ} \mathrm{C}$ for $30 \mathrm{~min}$ in order to sterilize the growth media. The flasks were inoculated with $10 \%(\mathrm{v} / \mathrm{v})$ G. xylinus inoculum, which was pre-grown for $24 \mathrm{~h}$ in a synthetic medium $(25 \mathrm{~g} / \mathrm{L}$ D-glucose, $5 \mathrm{~g} / \mathrm{L}$ yeast extract and $3 \mathrm{~g} / \mathrm{L}$ tryptone, $\mathrm{pH}$ 5.0). The flasks were incubated statically at $30^{\circ} \mathrm{C}$ for 7 days, after which the yield of $\mathrm{BC}$ and the $\mathrm{pH}$ value were measured. Samples of the culture fluid were taken for analysis of the monosaccharide content.

A second series of experiments consisted of four-fold diluted fiber sludge hydrolysates and a glucose reference with similar monosaccharide content. The experiments were performed as described above but with $100 \mathrm{~mL}$ of medium in $250-\mathrm{mL}$ flasks. The time of incubation was increased from 7 days in the first experiment to 14 days. After 14 days of static incubation, the $\mathrm{BC}$ membranes were collected by filtration and were then dried to constant weight at $105^{\circ} \mathrm{C}$. After that, the $\mathrm{BC}$ was weighed for calculation of the yield.

The yield of $\mathrm{BC}$ on initial reducing sugar $(\mathrm{g} / \mathrm{g})$ was calculated by dividing the volumetric yield of $\mathrm{BC}$ with the initial concentration of reducing sugar. The yield of $\mathrm{BC}$ on consumed sugar $(\mathrm{g} / \mathrm{g})$ was calculated by using the following equation:

$$
\begin{aligned}
& \text { BC yield on consumed sugar }(g / g) \\
& =\frac{\mathrm{BC}(g)}{\text { Initial reducing sugar }- \text { residual sugar }(g)}
\end{aligned}
$$

For characterization of $\mathrm{BC}$ membranes, the cellulose pellicle was soaked in a $0.1 \mathrm{M}$ solution of sodium hydroxide $\left(60 \mathrm{~min}, 80^{\circ} \mathrm{C}\right)$ to remove impurities, such as culture medium and trapped bacterial cells. A second wash was performed with deionized water at the same temperature and for the same period of time. The BC pellicle was then washed with deionized water until the $\mathrm{pH}$ of washing water was neutral.

\section{Production of cellulase}

Enzyme production with Trichoderma reesei Rut C-30 was performed by using spent hydrolysates obtained after BC production, and with the addition of $2 \%(\mathrm{w} / \mathrm{v})$ of the corresponding dried waste fiber sludge. Reference medium, which was used as a control, was based on glucose $(10 \mathrm{~g} / \mathrm{L})$ with $2 \%(\mathrm{w} / \mathrm{v})$ additional waste fiber sludge. Separate cultures with reference medium were used for SAFS and SIFS. Each of a series of 500-mL flasks contained $100 \mathrm{~mL}$ spent hydrolysate supplemented with $0.1 \%(\mathrm{w} / \mathrm{v})$ tryptone, $0.05 \%$ citric acid, $2 \%$ Vogel's media [23], and $0.015 \%$ Tween 80. The flasks containing the media were autoclaved at $110^{\circ} \mathrm{C}$ for $30 \mathrm{~min}$. The flasks were then inoculated with
$10 \%(\mathrm{v} / \mathrm{v})$ of a suspension of $T$. reesei pellets from a culture with glucose-based reference medium that was pre-grown at $30^{\circ} \mathrm{C}$ for $36 \mathrm{~h}$. The cultivations were carried out at $28^{\circ} \mathrm{C}$ and $160 \mathrm{rpm}$ for the following 8 days.

\section{Enzyme activity assay}

The cellulase activity was measured using a reducing sugar assay developed for determination of xylanase activity and based on dinitrosalicylic acid (DNS) [24], but with $1 \%(\mathrm{w} / \mathrm{v})$ of carboxymethyl cellulose (CMC) as substrate instead of xylan, and using a buffer consisting of $50 \mathrm{mM}$ citric acid ( $\mathrm{pH}$ 5.0). A mixture containing $0.9 \mathrm{~mL}$ substrate solution and $0.1 \mathrm{~mL}$ enzyme sample was incubated at $50^{\circ} \mathrm{C}$ for $10 \mathrm{~min}$. Blanks containing (A) enzyme but no substrate and (B) substrate but no enzyme were included with all assays of enzyme activity, and the values obtained for the samples were corrected using the blank values. One unit of cellulase activity equals formation of $1 \mu \mathrm{mol}$ glucose from CMC per min at $\mathrm{pH} 5.0$ and $50^{\circ} \mathrm{C}$. The activity of the culture fluids were calculated as the volumetric activity $(\mathrm{U} / \mathrm{mL})$ [one unit (U) equals 16.67 nkat].

\section{Analysis of sugars and acetic acid}

The concentrations of arabinose, galactose, glucose, xylose, and mannose were determined using high-performance anion-exchange chromatography (HPAEC). The system used was an ICS-3000 from Dionex (Sunnyvale, CA, USA) with an electrochemical detector. The separation was performed with a CarboPac PA20 $(3 \times 150 \mathrm{~mm})$ separation column equipped with a CarboPac PA20 $(3 \times 30 \mathrm{~mm})$ guard column (Dionex). Elution was performed with a $2 \mathrm{mM}$ solution of $\mathrm{NaOH}$ during $25 \mathrm{~min}$, followed by regeneration at $5 \mathrm{~min}$ with $100 \mathrm{mM} \mathrm{NaOH}$, and equilibration for 15 min with $2 \mathrm{mM} \mathrm{NaOH}$ (Sodium hydroxide solution for IC, Sigma-Aldrich, Steinheim, Germany). The flow rate was $0.4 \mathrm{~mL} / \mathrm{min}$.

The concentration of acetic acid was determined with HPAEC by using the ICS-3000 system and its conductivity detector. The separation was performed with an IonPac AS15 $(4 \times 250 \mathrm{~mm})$ separation column equipped with an IonPac AG15 $(4 \times 50 \mathrm{~mm})$ guard column (Dionex). The mobile phase consisted of a $35 \mathrm{mM}$ solution of $\mathrm{NaOH}$ (Sodium hydroxide solution for IC, Sigma-Aldrich), and the flow rate was $1.2 \mathrm{~mL} / \mathrm{min}$.

\section{Tensile strength of wet $\mathrm{BC}$ membranes}

The washed BC pellicle was cut into $40 \mathrm{~mm}$ long and $10 \mathrm{~mm}$ wide strips for analysis of tensile strength. The tensile strength of the wet $\mathrm{BC}$ was measured by using a universal testing machine (H5K-S, Hounsfield Test Equipment Ltd., UK) operating at a crosshead speed of $50 \mathrm{~mm} / \mathrm{min}$. All data for determination of tensile strength were collected under the same conditions. The tensile strength 
(in megapascal, $\mathrm{MPa}$, or $\mathrm{N} / \mathrm{mm}^{2}$ ) was calculated by dividing the tensile force by the area of the cross section of the BC strips. Each test was performed by using 10 samples and mean values of the strength of $\mathrm{BC}$ are given.

\section{Electron microscopy}

The purified BC pellicle was dried by using a vacuum freeze dryer (LyoQuest-55 Plus, Telstar, Spain) and the samples were then coated with gold (E-1045, Hitachi, Tokyo, Japan). Analysis of the structure of the BC was performed by using a Field-Emission Scanning Electron Microscope (FESEM) (S-4800, Hitachi) at 15, 25 or $35 \mathrm{kV}$. The amplification was 20,000 . The analysis of the diameter of 100 fibers was performed by using the software ImageJ [25].

\section{Degree of crystallinity of $B C$}

$\mathrm{X}$-ray diffraction (XRD) was used to examine the crystallinity of freeze-dried $\mathrm{BC}$ after alkaline washing. XRD spectra were recorded by using a D/Max-2550PC diffractometer (Rigaku, Tokyo, Japan) at $40 \mathrm{kV}$ and $200 \mathrm{~mA}$. Angular scanning was performed at $5-60^{\circ}(2 \theta)$ and $1 \% \mathrm{~min}$. Calculations of the degree of crystallinity were based on the empirical method of Segal et al. [26].

\section{Abbreviations}

BC: Bacterial cellulose; SAFS: Fiber sludge from sulfate process; SIFS: Fiber sludge from sulfite process; G. xylinus: Gluconacetobacter xylinus; T. reesei: Trichoderma reesei; DW: Dry weight; CMC: Carboxymethyl cellulose; SEM: Scanning electron microscope; FESEM: Field-emission scanning electron micrographs; TCA: Tricarboxylic acid cycle; A. niger: Aspergillus niger; rpm: Revolutions per minute; DNS: Dinitrosalicylic acid; HPAEC: Highperformance anion-exchange chromatography; XRD: X-ray diffraction.

\section{Competing interests}

The authors declare that they have no competing interests.

\section{Authors' contributions}

All work has been carried out by AC, XG, SJT and SW under the supervision of $L J$ and FH. AC and XG contributed equally to this work and therefore should be considered as co-first-authors. All authors read and approved the final manuscript.

\section{Authors' information \\ $A C$ and $X G$ are doctoral students with interests in the areas of enzymatic saccharification and bioconversion of biomass for the production of value- added products including biofuels and biopolymers. SJT was a master student and now has a job in the biomedical area. SW is a postdoctoral researcher with interest in enzyme chemistry and technology. LJJ is a professor of biochemistry and biotechnology. His research is focused on biotechnology for the biorefining of lignocellulose. He is leader of the Biochemical Platform of the Bio4Energy research initiative (www.bio4energy.se). $\mathrm{FH}$ is a professor of biotechnology and bioengineering. His interests include low-cost production of bacterial cellulose and enzymes, bioconversion of renewable resources to high value-added products, as well as applications of biomaterials in biomedicine and functional materials.}

\section{Acknowledgments}

This investigation was funded by Program for New Century Excellent Talents in University, by the Science and Technology Commission of Shanghai Municipality (12nm0500600 and 11230700600), the Swedish Research Council (348-2006-6705), the Fundamental Research Funds for the Central Universities, the Kempe Foundations, the Swedish Energy Agency, and Bio4Energy (www.bio4energy.se). One of the authors (AC) was supported by
SEKAB E-Technology AB (Örnsköldsvik, Sweden) through the Umeå University Industrial Graduate School.

\section{Author details}

${ }^{1}$ China-Sweden Associated Research Laboratory in Industrial Biotechnology, College of Chemistry, Chemical Engineering and Biotechnology, Donghua University, Shanghai 201620, China. ${ }^{2}$ Department of Chemistry, Umeå University, SE-901 87, Umeå, Sweden. ${ }^{3}$ Group of Microbiological Engineering and Industrial Biotechnology, College of Chemistry, Chemical Engineering and Biotechnology, Donghua University, 201620, Shanghai, China.

Received: 5 September 2012 Accepted: 14 February 2013

Published: 16 February 2013

\section{References}

1. Bielecki S, Krystynowicz A, Turkiewicz M, Kalinowska H: Bacterial cellulose. In Biopolymers (Polysaccharides I: Polysaccharides from Prokaryotes). Volume 5. Edited by Vandamme J, Baets SD, Steinbüchel A. Weinheim: Wiley-VCH Verlag; 2002:37-90.

2. Nakagaito AN, Iwamoto S, Yano H: Bacterial cellulose: the ultimate nanoscalar cellulose morphology for the production of high-strength composites. Appl Phys A: Mater Sci Process 2005, 80:93-97.

3. Gardner DJ, Oporto GS, Mills R, Azizi Samir MAS: Adhesion and surface issues in cellulose and nanocellulose. J Adhes Sci Technol 2008, 22:545-567.

4. Klemm D, Schumann D, Kramer F, Heßler N, Hornung M, Schmauder HP, Marsch S: Nanocelluloses as innovative polymers in research and application. Adv Polym Sci 2006, 205:49-96.

5. Czaja WK, Young DJ, Kawecki M, Brown RM Jr: The future prospects of microbial cellulose in biomedical applications. Biomacromolecules 2007, 8:1-12.

6. Petersen N, Gatenholm P: Bacterial cellulose-based materials and medical devices: current state and perspectives. App/ Microbiol Biotechnol 2011, 91:1277-1286

7. Jiang G, Qiao J, Hong F: Application of phosphoric acid and phytic acid doped bacterial cellulose as novel proton-conducting membranes to PEMFC. Int J Hydrogen Energy 2012, 37:9182-9192.

8. Gao QY, Shen XY, Lu XK: Regenerated bacterial cellulose fibers prepared by the NMMO $\mathrm{H}_{2} \mathrm{O}$ process. Carbohyd Polym 2011, 83:1253-1256.

9. Hong F, Qiu K: An alternative carbon source from konjac powder for enhancing production of bacterial cellulose in static cultures by a model strain Acetobacter aceti subsp. xylinus ATCC 23770. Carbohyd Polym 2008, 72:545-549.

10. Hong F, Zhu YX, Yang G, Yang XX: Wheat straw acid hydrolysate as a potential cost-effective feedstock for production of bacterial cellulose. J Chem Technol Biot 2011, 86:675-680.

11. Chen L, Hong F, Yang X, Han S: Biotransformation of wheat straw to bacterial cellulose and its mechanism. Bioresource Technol 2012, doi:10.1016/j.biortech.2012.10.029

12. Hong F, Guo X, Zhang S, Han S-F, Yang G, Jönsson LJ: Bacterial cellulose production from cotton-based waste textiles: enzymatic saccharification enhanced by ionic liquid pretreatment. Bioresource Technol 2012, 104:503-508.

13. Keshk SMAS, Sameshima K: Evaluation of different carbon sources for bacterial cellulose production. Afr J Biotechnol 2005, 4:478-482.

14. Thompson DN, Hamilton MA: Production of bacterial cellulose from alternate feedstocks. Appl Biochem Biotech 2001, 91-93:503-513.

15. Ishihara M, Matsunaga $M$, Hayashi $N$, Tišler V: Utilization of D-xylose as carbon source for production of bacterial cellulose. Enzyme Microb Tech 2002, 31:986-991.

16. Dahman $\mathrm{Y}$, Jayasuriya KE, Kalis M: Potential of biocellulose nanofibers production from agricultural renewable resources: preliminary study. Appl Biochem Biotechnol 2010, 162:1647-1659.

17. Ross $\mathrm{P}$, Mayer R, Benziman M: Cellulose biosynthesis and function in bacteria. Microbiol Rev 1991, 55:35-58.

18. Alriksson $B$, Rose $S H$, van Zyl WH, Jönsson $\sqcup$ : Cellulase production from spent lignocellulosic hydrolysates with recombinant Aspergillus niger. Appl Environ Microb 2009, 75:2366-2374.

19. Cavka A, Alriksson B, Rose SH, van Zyl WH, Jönsson LJ: Biorefining of wood: combined production of ethanol and xylanase from waste fiber sludge. $J$ Ind Microbiol Biot 2011, 38:891-899. 
20. Shin CS, Lee JP, Lee JS, Park SC: Enzyme production of Trichoderma reese Rut C-30 on various lignocellulosic substrates. Appl Biochem Biotechnol 2000, 84-86:237-245.

21. Szengyel Z, Zacchi G, Réczey K: Cellulase production based on hemicellulose hydrolysate from steam-pretreated willow. Appl Biochem Biotechnol 1997, 63-65:351-362.

22. Szengyel Z, Zacchi G, Vartam A, Réczey K: Cellulase production of Trichoderma reesei Rut C-30 using steam-pretreated spruce. Appl Biochem Biotechnol 2000, 84-86:679-691.

23. Vogel HJ: Distribution of lysine pathways among fungi: evolutionary implications. Am Naturalist 1964, 98:435-446.

24. Bailey MJ, Biely P, Poutanen K: Interlaboratory testing of methods for assay of xylanase activity. J Biotechnol 1992, 23:257-270.

25. Schneider CA, Rasband WS, Eliceiri KW: NIH Image to Image J: 25 years of image analysis. Nat Methods 2012, 9:671-675.

26. Segal L, Creely JJ, Martin AE, Conrad CM: An empirical method for estimating the degree of crystallinity of native cellulose using the X-ray diffractometer. Textile Res J 1959, 29:786-794.

doi:10.1186/1754-6834-6-25

Cite this article as: Cavka et al:: Production of bacterial cellulose and enzyme from waste fiber sludge. Biotechnology for Biofuels 2013 6:25.

\section{Submit your next manuscript to BioMed Central and take full advantage of:}

- Convenient online submission

- Thorough peer review

- No space constraints or color figure charges

- Immediate publication on acceptance

- Inclusion in PubMed, CAS, Scopus and Google Scholar

- Research which is freely available for redistribution 